\title{
Efeito da temperatura e luz na germinação de sementes de Luetzelburgia auriculata (Alemão) Ducke - Fabaceae
}

Francisco Carlos Barboza Nogueira ${ }^{1,3}$, José Wêndney Lima e Silva ${ }^{2}$, Antônio Marcos Esmeraldo Bezerra ${ }^{2}$ e Sebastião Medeiros Filho ${ }^{2}$

Recebido em 13/03/2011. Aceito em 19/06/2012

\begin{abstract}
RESUMO
(Efeito da temperatura e luz na germinação de sementes de Luetzelburgia auriculata (Alemão) Ducke - Fabaceae). Luetzelburgia auriculata (Alemão) Ducke é uma espécie arbórea nativa do Brasil, pertencente à família das Fabaceae, importante pela utilidade econômica de sua madeira na construção civil, marcenaria e produção de lenha e carvão. O experimento foi conduzido em laboratório para avaliar o processo germinativo de suas sementes, na ausência e presença de luz, submetido às temperaturas constantes de $20,25,30,35,40^{\circ} \mathrm{C}$ e alternada de $20-40^{\circ} \mathrm{C}$, sob fotoperíodo de 12 horas e escuro contínuo. As variáveis avaliadas foram porcentagem, velocidade e tempo médio de germinação. As sementes germinaram na presença e na ausência de luz, com as maiores médias alcançadas em $20-40{ }^{\circ} \mathrm{C}, 20^{\circ} \mathrm{C}$, $25^{\circ} \mathrm{C}, 30^{\circ} \mathrm{C} \mathrm{e} 35^{\circ} \mathrm{C}$ e as menores em $40^{\circ} \mathrm{C}$. Suas sementes são indiferentes à luz. A faixa ótima de temperatura entre 25 a $30^{\circ} \mathrm{C}$ possibilitou alta germinabilidade e menor tempo médio de germinação.
\end{abstract}

Palavras-chave: fotoperíodo, sementes florestais, tamanho de sementes, zona semiárida

\begin{abstract}
(The effect of temperature and light on Luetzelburgia auriculata (Alemão) Ducke seed germination). Luetzelburgia auriculata (Alemão) Ducke is a native tree species in Brazil with wood that is economically important in construction, carpentry and production of firewood and charcoal. A laboratory experiment was carried out to analyze seed germination of L. auriculata in the presence and absence of light, as well as constant temperatures of 20,25,30,35, $40{ }^{\circ} \mathrm{C}$ and alternating temperatures of $20-45^{\circ} \mathrm{C}$, all under a photoperiod of 12 hours and continuous darkness. The variables evaluated were: percentage, speed and medium time of germination. The seeds germinated in the presence and absence of light, the highest percentages of germination were at $20-40,20,25,30$ and $35^{\circ} \mathrm{C}$ and the lowest at 40 ${ }^{\circ} \mathrm{C}$. The seeds were indifferent to light. The optimum temperature range was between 25 and $30^{\circ} \mathrm{C}$, which promoted a high germination rate and a lower average germination time.
\end{abstract}

Key words: Forest seeds, photoperiod, seed size, semi-arid zone

\section{Introdução}

Luetzelburgia auriculata (Alemão) Ducke, Fabaceae, subfamília Faboideae, ocorre no Nordeste brasileiro, principalmente no Piauí e sul do Ceará, sendo conhecida pelos nomes vulgares de pau-mocó, pau-de-mocó, pau-serrote e pau-de-chapada (Lorenzi 2008). Este autor destaca a utilidade de sua madeira na construção civil em acabamentos internos, em marcenaria e para lenha e carvão. Considera árvore rústica e adaptada a terrenos secos e pedregosos e que não pode faltar em plantios mistos destinados à recomposição de áreas degradadas de preservação permanente.

As espécies lenhosas nativas têm a semente como principal meio de propagação. Por isso, a obtenção de informações sobre a germinação de sementes no que diz respeito aos efeitos da luz e temperatura é essencial para entender o sucesso do estabelecimento das espécies em seu habitat. A velocidade de absorção de água e a modificação

\footnotetext{
${ }^{1}$ Universidade Federal do Ceará, Programa de Pós-Graduação em Ecologia e Recursos Naturais, Departamento de Biologia, Fortaleza, CE, Brasil

${ }^{2}$ Universidade Federal do Ceará, Departamento de Fitotecnia, Fortaleza, CE, Brasil

${ }^{3}$ Autor para correspondência: fcbarbozanogueira@hotmail.com
} 
na velocidade de reações químicas provocadas pela temperatura podem interferir no desdobramento, no transporte das reservas e na síntese de substâncias para as plântulas (Rosa \& Ferreira 2001). Assim, estudos de germinação de sementes são importantes para fornecer não só informações úteis à tecnologia de sementes como também para a compreensão da ecofisiologia das espécies vegetais (Borghetti \& Ferreira 2004).

Temperatura e luz são os principais fatores ambientais que afetam a germinação de sementes no solo, desde que haja disponibilidade de água e oxigênio (Rosa \& Ferreira 2001; Velten \& Garcia 2005). De acordo com Pons (2000), a temperatura afeta a germinação e pode induzir a dormência de sementes. Algumas sementes, sob baixas temperaturas são indiferentes à luz, germinando tanto na luz como no escuro, porém, em temperaturas amenas, apresentam fotossensibilidade, germinando somente na luz e, quando em temperaturas mais elevadas, podem apresentar dormência ou mesmo a perda de viabilidade (Takaki 2005).

A relação entre germinação e limites de temperaturas é uma característica de cada espécie (Ramos \& Varela 2003) e está freqüentemente associada às temperaturas que as plantas ficam expostas durante a fase de crescimento (Villalobos \& Peláez 2001). Para muitas espécies vegetais, quando são fornecidas condições adequadas de luz e umidade, a temperatura predominante determina não só a fração de sementes que germina como também a velocidade de germinação (Oliveira \& Garcia 2005). Em algumas espécies a presença de luz, de certa forma, favorece a germinação das sementes, designando-se este efeito como fotoblástico positivo; em outras espécies o comportamento germinativo das sementes é melhor na ausência do que na presença de luz, o que se designa como fotoblastismo negativo; outras são neutras quanto à germinação na presença ou ausência de luz (Vásques-Yanes \& Orozco-Segovia 1993).

O tamanho da semente é uma de suas características que estão associadas com a temperatura e luz. Em geral, sementes pequenas se apresentam associadas com a presença de luz em habitats abertos (Jankowska-Blaszczuk \& Daws 2007) e temperaturas alternadas (Velten \& Garcia 2005). Enquanto, sementes grandes não apresentam esses requerimentos e são capazes de originar plântulas maiores de crescimento inicial lento que emergem de maiores profundidades do solo (Jurado \& Westoby 1992; Leishman et al. 2000). O tamanho da semente e a relação entre necessidade de luz para germinar e a flutuação de temperaturas parece estar ligada a estratégia ecológica em evitar a germinação em locais muito profundos do solo. Nesses locais, as sementes pequenas teriam dificuldade de emergirem (Velten \& Garcia 2005).

O experimento foi realizado para responder qual a melhor faixa de temperatura e efeitos de luz para a germinação das sementes de Luetzelburgia auriculata. Sabe-se que L. auriculata floresce durante a estação seca (agosto-setembro) a cada dois anos, seguida pela frutificação na mesma estação (Lorenzi 2008) e que apresenta germinação epígea e plântula fanerocotiledonar (Silva et al. 1995). Lima (1990) sugere que espécies com germinação fanerocodiledonar seriam mais abundantes em matas secas com alta disponibilidade de luz. Apesar disso, Leishman et al. (2000) relatam a forte dependência de espécies com grandes sementes para ambientes sombreados. Por outro lado, em regiões semiáridas a temperatura é mais variável na superfície do solo e próximo desta (Gutierrez et al. 1988). Por esse motivo, considerou-se a hipótese de que as sementes $L$. auriculata apresentam melhores índices de germinação na presença de luz e em ampla faixa de temperatura. Para a previsão desta hipótese, buscou-se relatar os efeitos da luz e diferentes temperaturas e as interações destes fatores através da porcentagem de germinação, do índice de velocidade de germinação e do tempo médio de germinação sobre as sementes de Luetzelburgia auriculata.

\section{Material e métodos}

\section{Local de coleta e armazenamento}

Frutos maduros de Luetzelburgia auriculata foram coletados no mês de outubro de 2010, manualmente, de dez árvores selecionadas ao acaso localizadas às margens do rio Palhano, no distrito de Pedras, município de Russas, Ceará. O clima do município de Russas é classificado como Tropical Quente Semiárido, com pluviosidade média anual de $857,7 \mathrm{~mm}$ e temperatura média de $26^{\circ} \mathrm{C}$ a $28^{\circ} \mathrm{C}$. O período chuvoso ocorre de janeiro a abril (Ipece 2011).

Os frutos foram acondicionados em sacos de polietileno e conduzidos ao Laboratório de Análise de Sementes do Departamento de Fitotecnia do Centro de ciências Agrárias, da Universidade Federal do Ceará - UFC, onde foram colocados para secar a pleno sol. No Laboratório, após a secagem, com ajuda de estilete, se fez a extração das sementes manualmente. As sementes foram depositadas em saco de polietileno e armazenadas em câmara fria na temperatura aproximada de $10^{\circ} \mathrm{C}$ até o início do experimento.

\section{Biometria das sementes}

Foram escolhidas ao acaso, após serem misturadas, 100 sementes para medição individual. Mediu-se comprimento, largura e espessura utilizando-se paquímetro digital. O comprimento foi medido da base até o ápice e a largura e espessura medidas na linha mediana das sementes. Os dados obtidos foram submetidos à análise descritiva, onde se calculou com ajuda do aplicativo Excel, média aritmética, desvio padrão, erro padrão, coeficiente de variação e intervalo de confiança. A determinação do número de sementes por quilograma e peso de 1.000 sementes foi realizada segundo recomendações das Regras para Análise de Sementes (Brasil 2009). Para essa determinação, utilizou-se balança analítica. 


\section{Teor de umidade}

Foram utilizadas quatro repetições de 25 sementes, que foram colocadas em cápsulas de alumínio e levadas para estufa a $105^{\circ} \mathrm{C}$ pelo período de 24 horas. Para a determinação dos pesos, foi feito primeiro o peso da cápsula vazia, depois o peso da cápsula com as sementes (PU) e após 24 horas foi feito o peso das cápsulas com as sementes (PS). Para a determinação do teor de umidade utilizou-se a seguinte fórmula: $\mathrm{U} \%=(\mathrm{PU}-\mathrm{PS}) / \mathrm{PU}{ }^{*} 100$,

Onde:

$\mathrm{U} \%=$ Teor de umidade

$\mathrm{PU}=$ Peso úmido

PS $=$ Peso seco.

\section{Teste de germinação}

As sementes foram desinfetadas com hipoclorito de sódio a $5 \%$, durante 15 minutos e posteriormente lavadas em água corrente, segundo método proposto nas Regras para Análise de Sementes (Brasil 2009). Foram colocadas para germinar em duas folhas de papel de filtro germitest, dispostas em placas de Petri de $14 \mathrm{~cm}$ de diâmetro, umedecidas com água destilada na proporção de 2,5 vezes o peso do papel. Quando necessário, as folhas foram reumedecidas.

As placas de Petri foram acondicionadas em germinadores regulados para os regimes de temperaturas constante e alternada. Em temperatura constante, as sementes foram expostas a valores que variaram de 20 a $40^{\circ} \mathrm{C}$, com intervalos de $5^{\circ} \mathrm{C}$. Em temperatura alternada, foi testada a amplitude térmica de 20 e $40{ }^{\circ} \mathrm{C}$. Nos dois regimes de temperatura as sementes foram submetidas ao fotoperíodo de 12 horas e escuro contínuo. Nos tratamentos em claro as placas de Petri foram colocadas dentro de sacos plásticos transparentes para evitar a perda de água. Para o tratamento no escuro, a total ausência de luz foi obtida envolvendo-se as placas de Petri em folhas de papel alumínio e posteriormente colocadas dentro de sacos plásticos pretos. A luz foi fornecida por lâmpadas fluorescentes de $20 \mathrm{w}$ (luz branca) localizadas no interior dos germinadores, e no caso das temperaturas alternadas o período luminoso correspondeu à temperatura mais elevada. Para os tratamentos referentes à ausência de luz, as contagens foram feitas sob luz verde de segurança, conforme recomendam Felippe et al. (1983).

A avaliação da germinação foi diária, sendo consideradas sementes germinadas as que apresentaram emissão de radícula com $2 \mathrm{~mm}$. Ao final do teste, que teve duração de 25 dias, foram determinados porcentagem de germinação, índice de velocidade de germinação e tempo médio de germinação. $O$ índice de velocidade de germinação (IVG) foi calculado pelo somatório do número de plântulas normais germinadas a cada dia $\left(G_{1}, G_{2}, G_{3} \ldots G_{n}\right)$, dividido pelo número de dias decorridos $\left(\mathrm{N}_{1}, \mathrm{~N}_{2}, \mathrm{~N}_{3} \ldots \mathrm{N}_{\mathrm{n}}\right)$ entre a semeadura e a germinação, de acordo com a fórmula descrita por Maguire (1962): $I V G=G_{1} / N_{1}+G_{2} / N_{2}+G_{3} / N_{3}+\ldots+G_{n} / N_{n}$.
O tempo médio de germinação foi calculado de acordo com a fórmula apresentada por Labouriau (1983):

$$
\mathrm{t}=\frac{\sum_{\mathrm{n}_{\mathrm{i}}} \cdot \mathrm{t}_{\mathrm{i}}}{\sum_{\mathrm{n}}} \text { dias, onde: }
$$

$\mathrm{t}$ = tempo médio de germinação;

$\mathrm{n}_{\mathrm{i}}=$ número de sementes germinadas num intervalo de tempo;

$\mathrm{n}=$ número total de sementes germinadas;

$\mathrm{t}_{\mathrm{i}}=$ dias de germinação.

\section{Delineamento experimental e análise estatística}

Os testes de germinação foram conduzidos com 1.200 sementes em um delineamento inteiramente casualizado, num esquema fatorial de $6 \times 2$ (temperaturas $\times$ regimes de luz), com quatro repetições de 25 sementes para cada tratamento.Os dados de germinação, expressos em porcentagem, foram transformados em arco seno da raiz quadrada da proporção. Em seguida, proporção, velocidade e tempo médio de germinação foram submetidos à análise de variância (ANOVA). As comparações entre as médias foram feitas pelo teste de Tukey ao nível de 5\% de probabilidade (Santana \& Ranal 2004). A análise estatística foi realizada utilizando-se o aplicativo computacional SISVAR (Ferreira 2003).

\section{Resultados}

As sementes de Luetzelburgia auriculata apresentam desuniformidade quanto ao tamanho, apresentando variação no comprimento (17,14 a 21,76 mm), largura (9,07 a 11,73 $\mathrm{mm}$ ) e espessura (3,95 a $6,49 \mathrm{~mm})$. O peso das sementes variou de $0,23 \mathrm{~g}$ a $0,68 \mathrm{~g}$. . As frequências dos comprimentos, largura, espessura e peso podem ser observadas na Fig. 1 A-D, com as respectivas médias. O peso de 1.000 sementes foi de $480,68 \mathrm{~g}$, com $5,00 \%$ de umidade, o que permite inferir que em um quilograma de sementes de Luetzelburgia auriculata pode conter 2.080 sementes.

As seis temperaturas analisadas foram determinantes na germinação das sementes de Luetzelburgia auriculata, com as maiores médias alcançadas em $20-40^{\circ} \mathrm{C}, 20^{\circ} \mathrm{C}, 25^{\circ} \mathrm{C}, 30$ ${ }^{\circ} \mathrm{C}$ e $35^{\circ} \mathrm{C}$, tanto no claro quanto no escuro, e as menores em $40^{\circ} \mathrm{C}$ (Tab.1).

O menor índice de velocidade de germinação foi obtido sob luz na temperatura de $40^{\circ} \mathrm{C}(0,37)$ que diferiu estatisticamente dos demais tratamentos, com exceção das temperaturas de 20 e $25^{\circ} \mathrm{C}$ ( 2,23 e 4,29 , respectivamente) e com todas as temperaturas submetidas ao escuro. $\mathrm{O}$ maior índice de velocidade de germinação ocorreu com temperatura de $25^{\circ} \mathrm{C}$ $(4,29$ no claro e 4,30 no escuro) e diferiu estatisticamente das demais temperaturas. O segundo maior valor foi com temperatura de $30^{\circ} \mathrm{C}$ (2,84 no claro e 3,31 no escuro), que também diferiu estatisticamente das outras temperaturas (Tab.2). 

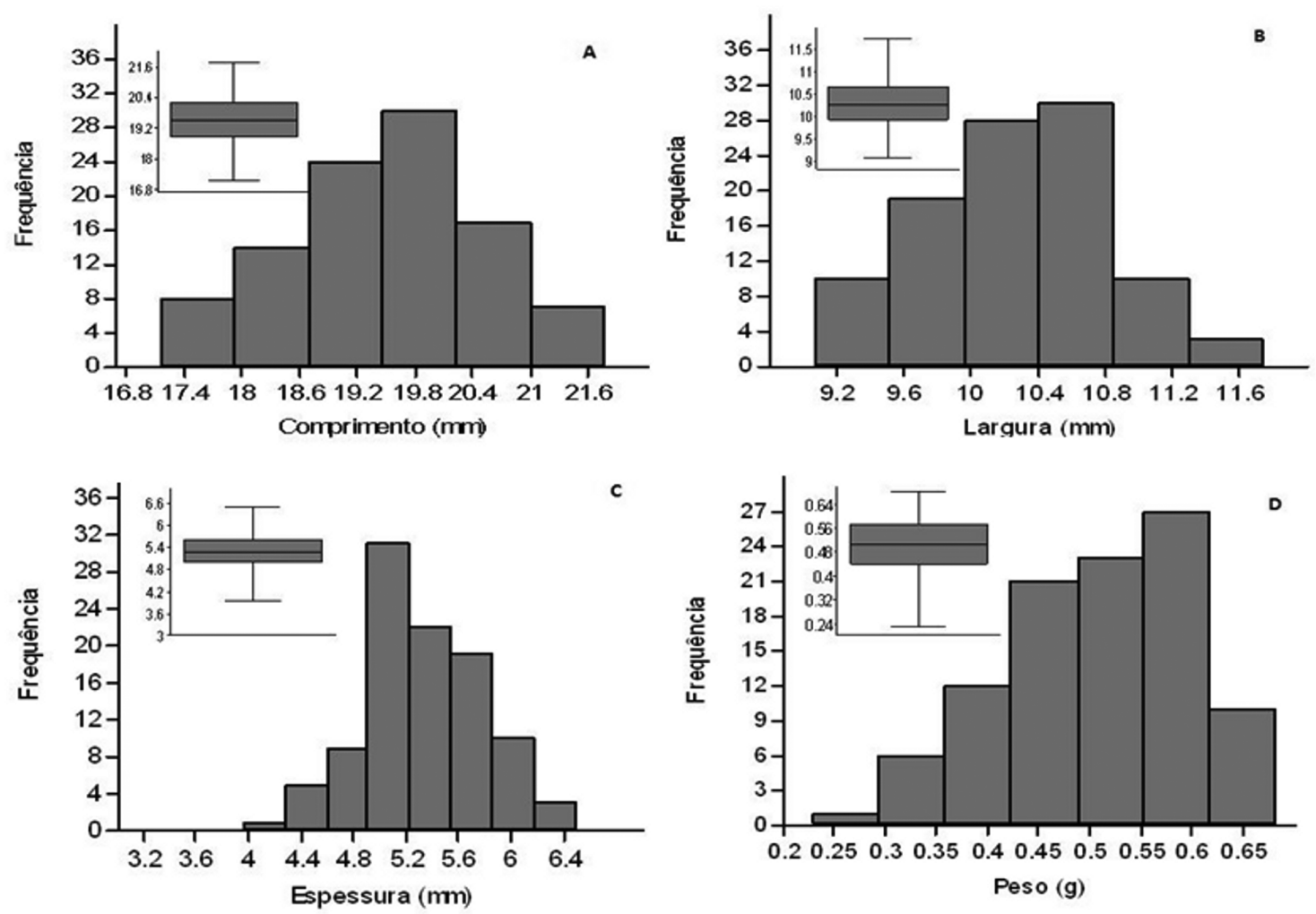

Figura 1. Frequências dos comprimentos, larguras, espessuras e pesos de sementes de Luetzelburgia auriculata.

Tabela 1. Médias da porcentagem de germinação de sementes de Luetzelburgia auriculata (Alemão) Ducke submetidas à germinação em seis temperaturas em condições de escuro e luz. Fortaleza, Ceará, 2011.

\begin{tabular}{|c|c|c|c|c|}
\hline \multirow{2}{*}{ Temperatura } & \multicolumn{2}{|c|}{ Dados transformados } & \multicolumn{2}{|c|}{ Dados originais (\% germ.) } \\
\hline & Escuro & Luz & Escuro & Luz \\
\hline $20^{\circ} \mathrm{C}$ & 85,89 aA & 87,11 aA & 98 & 99 \\
\hline $25^{\circ} \mathrm{C}$ & $87,11 \mathrm{aA}$ & 87,11 aA & 99 & 99 \\
\hline $30^{\circ} \mathrm{C}$ & $90 \mathrm{aA}$ & $81,34 \mathrm{aAB}$ & 100 & 97 \\
\hline $35^{\circ} \mathrm{C}$ & 78,5 aA & $69,65 \mathrm{aB}$ & 91 & 87 \\
\hline $40^{\circ} \mathrm{C}$ & $42,10 \mathrm{aB}$ & $27,85 \mathrm{bC}$ & 45 & 23 \\
\hline $20-40^{\circ} \mathrm{C}$ & $87,11 \mathrm{aA}$ & $79,16 \mathrm{aAB}$ & 99 & 95 \\
\hline${ }^{1} \mathrm{DMS}_{\mathrm{T} / \mathrm{L}}$ & 16,67 & & & \\
\hline${ }^{2} \mathrm{DMS}_{\mathrm{L} / \mathrm{T}}$ & 11,23 & & & \\
\hline CV\% & 10,41 & & & \\
\hline
\end{tabular}

Médias seguidas de mesma letra minúscula na linha e maiúscula na coluna, não diferem entre si pelo teste de Tukey a 5\% de significância.

${ }^{1}$ Diferença mínima significativa do teste de Tukey para o desdobramento Temperatura dentro de Luz.

${ }^{2}$ Diferença mínima significativa do teste de Tukey para o desdobramento de Luz dentro de Temperatura.

Analisando-se conjuntamente a porcentagem de germinação (Tab. 1) com o índice de velocidade de germinação (Tab. 2), se observa que os maiores percentuais de germinação foram semelhantes na luz e no escuro. Somente o tratamento com temperatura de $40^{\circ} \mathrm{C}$, mostrou menor percentual de germinação e menor índice de velocidade de germinação na condição de escuro e luz.

O maior tempo médio de germinação (em dias) ocorreu na temperatura de $40^{\circ} \mathrm{C}$, tanto no escuro quanto no claro
(15,31 e 16,24, respectivamente). Contudo, em temperatura alternada $20-40{ }^{\circ} \mathrm{C}$, em presença de luz $(15,61)$, não houve diferença estatística com a temperatura de $40^{\circ} \mathrm{C}$, no escuro e claro. $\mathrm{O}$ menor tempo médio de germinação foi alcançado na temperatura de $25^{\circ} \mathrm{C}(6,04$ no claro e 6,15 no escuro) e diferiu estatisticamente das demais temperaturas. O segundo menor valor foi registrado na temperatura de $30^{\circ} \mathrm{C}$ (8,67 no claro e 7,91 no escuro), que também diferiu estatisticamente das outras temperaturas (Tab.3). 
Tabela 2. Médias do índice de velocidade de germinação de sementes de Luetzelburgia auriculata (Alemão) Ducke submetidas à germinação em seis temperaturas em condição de escuro e luz. Fortaleza, Ceará, 2011.

\begin{tabular}{lcc}
\hline \multicolumn{1}{c}{ Temperatura } & Escuro & Luz \\
\hline $20-40{ }^{\circ} \mathrm{C}$ & $2,03 \mathrm{aC}$ & $1,56 \mathrm{bD}$ \\
$20^{\circ} \mathrm{C}$ & $2,08 \mathrm{aC}$ & $2,23 \mathrm{aC}$ \\
$25^{\circ} \mathrm{C}$ & $4,30 \mathrm{aA}$ & $4,29 \mathrm{aA}$ \\
$30^{\circ} \mathrm{C}$ & $3,31 \mathrm{aB}$ & $2,84 \mathrm{bB}$ \\
$35^{\circ} \mathrm{C}$ & $2,00 \mathrm{aC}$ & $1,59 \mathrm{bD}$ \\
$40^{\circ} \mathrm{C}$ & $0,75 \mathrm{aD}$ & $0,37 \mathrm{bE}$ \\
\hline
\end{tabular}

$\mathrm{CV} \%=9,42 ; \mathrm{DMS}_{\mathrm{T} / \mathrm{L}}=0,45 \mathrm{e} \mathrm{DMS}_{\mathrm{L} / \mathrm{T}}=0,30$

Médias seguidas de mesma letra minúscula na linha e maiúscula na coluna, não diferem entre si pelo teste de Tukey a 5\% de significância.

Tabela 3. Médias do tempo médio de germinação (em dias) de sementes de Luetzelburgia auriculata (Alemão) Ducke submetidas à germinação em seis temperaturas em condição de escuro e luz. Fortaleza, Ceará, 2011.

\begin{tabular}{lcc}
\hline \multicolumn{1}{c}{ Temperatura } & Escuro & Luz \\
\hline $20-40^{\circ} \mathrm{C}$ & $12,53 \mathrm{aC}$ & $15,61 \mathrm{bD}$ \\
$20^{\circ} \mathrm{C}$ & $12,23 \mathrm{aC}$ & $11,33 \mathrm{aC}$ \\
$25^{\circ} \mathrm{C}$ & $6,15 \mathrm{aA}$ & $6,04 \mathrm{aA}$ \\
$30^{\circ} \mathrm{C}$ & $7,91 \mathrm{aB}$ & $8,67 \mathrm{aB}$ \\
$35^{\circ} \mathrm{C}$ & $12,37 \mathrm{aC}$ & $15,38 \mathrm{bD}$ \\
$40^{\circ} \mathrm{C}$ & $15,31 \mathrm{aD}$ & $16,24 \mathrm{aD}$ \\
\hline $\mathrm{CV} \%=5,87 ; \mathrm{DMS}_{\mathrm{T} / \mathrm{L}}=1,45 \mathrm{e} \mathrm{DMS}_{\mathrm{L} / \mathrm{T}}=0,98$ & \\
\hline
\end{tabular}

Médias seguidas de mesma letra minúscula na linha e maiúscula na coluna, não diferem entre si pelo teste de Tukey a 5\% de significância.

\section{Discussão}

Ao rever as estratégias de germinação e crescimento de onze espécies lenhosas da Caatinga sem impedimento à germinação, Barbosa (2008) atribuiu às sementes de tamanho médio, valores variando de 12,0 a 14,6 x 10,0 a 13,0 mm e de tamanho grande àquelas superiores a esse intervalo. Pode-se considerar que sementes de Luetzelburgia auriculata estão para essa classificação, agrupadas na classe das sementes de grande tamanho. Na maioria dos habitats, o tamanho de sementes varia, normalmente, entre cinco a seis ordens de magnitude (Leishman et al. 2000; Jurado et al. 2001). Contudo, apesar de não existir tamanho de semente ideal para todos os propósitos de pesquisa, Leishman et al. (2000) afirmam que a massa de reserva representa a melhor fonte para discutir estabelecimento de plântulas. Para Milberg et al. (2000) espécies que apresentam grandes sementes são menos dependentes de luz que espécies com pequenas sementes. Os citados autores sugeriram que o requerimento por luz coevoluiu com a massa de sementes.

Com relação ao tamanho de sementes, as espécies vegetais que produzem pequenas sementes são mais susceptíveis à luz como um sinal de estímulo à germinação do que espécies com grandes sementes (Jankowska-Blaszczuk
\& Daws 2007), ou seja, espécies com grandes sementes são mais tolerantes à sombra. Este é um padrão bem conhecido para as florestas temperadas e para herbáceas européias a partir de uma variedade de habitats (Milberg et al. 2000), no entanto, ainda não descrito para a região semiárida do Nordeste brasileiro. Milberg et al. (2000) relataram a correlação evolutiva entre exigência de luz e tamanho de sementes, através da germinação de 54 espécies vegetais em banco de sementes no solo. Os resultados mostraram que a germinação se tornou menos dependente da luminosidade com o aumento no tamanho de sementes.

Grandes sementes são capazes de originar plântulas maiores, de crescimento inicial lento e que emergem de maiores profundidades do solo. Para Pons (2000), o significado mais obvio do requerimento por luz para desencadear a germinação é evitar maiores profundidades do solo, permitindo que plântulas alcancem os nutrientes disponíveis existentes na superfície. Jurado \& Westoby (1992) estudaram o crescimento de 32 plântulas em relação ao tamanho da semente, na região árida central da Austrália. Para os autores, espécies com grandes sementes são, em geral, prováveis de terem plântulas maiores, por algum tempo após as chuvas, pelo menos por 20 dias, até o consumo total da reserva da semente. Enquanto, plântulas provenientes de pequenas sementes, usualmente, têm uma rápida taxa de crescimento e germinam melhor que sementes grandes. Este é outro padrão não observado em Floresta Temperada, pois segundo Jankowska-Blaszczuk \& Daws (2007) plântulas de sementes pequenas são inicialmente pequenas e, especialmente, em condições de pouca luz irão ficar relativamente pequenas por períodos prolongados de tempo.

Outro aspecto a observar com relação ao tamanho de semente é a capacidade das grandes sementes emergirem de camadas mais profundas do solo. Buckley (1982) argumenta que as sementes ao atingirem níveis mais profundos no solo têm menor risco de dissecação, em ambientes áridos, do que aquelas na superfície do solo durante o estabelecimento. Por este fato representar uma vantagem para as grandes sementes, Jurado \& Westoby (1992) afirmam que elas necessitariam ser enterradas mais profundamente que pequenas sementes. No entanto, não existe evidência que isto aconteça e, na verdade, pequenas sementes parecem mais prováveis de serem enterradas ao caírem em superfícies rachadas do solo ou em pequenos buracos. Contudo, é esperado que pequenas sementes somente germinem após romperem pequena distância até a superfície do solo (Bond et al. 1999).

Além disso, temperaturas alternadas podem funcionar como um mecanismo de detecção de profundidade da semente no solo (Jankowska-Blaszczuk \& Daws 2007). Apesar de grandes sementes utilizarem a luz para germinar, elas podem germinar no escuro na presença de temperaturas alternadas (Thompson \& Grime 1983). Como as flutuações de temperatura do solo podem ser experimentadas por sementes enterradas em maior profundidade do solo (Jankowska-Blaszczuk \& Daws 2007), esta sinalização (temperatura alternada) 
pode ser inadequada para espécies com pequenas sementes (Thompson \& Grime 1983). Contudo esse não é o caso de Luetzelburgia auriculata que possui grandes sementes e não se espera que estas alcancem grande profundidade no solo.

Para desencadear o processo germinativo, em sementes de Luetzelburgia auriculata, é desnecessária a incidência ou ausência de luminosidade. Por isso, estas sementes podem ser caracterizadas como fotoblásticas neutras ou indiferentes à luz, por germinarem na presença luz e ausência (Santos et al. 2005) As sementes germinaram satisfatoriamente nas seis temperaturas testadas, com exceção da temperatura de $40{ }^{\circ} \mathrm{C}$. No entanto, a faixa entre 25 a $30{ }^{\circ} \mathrm{C}$ pode ser considerada ótima, pois possibilitou alta germinabilidade e menor tempo médio de germinação (Camara et al. 2008; Simão \& Takaki 2008).

A porcentagem de germinação de sementes de Luetzelburgia auriculata em temperatura alternada $\left(20-40^{\circ} \mathrm{C}\right)$ foi alta $(87,11 \%)$. Em geral, a alternância de temperatura é um mecanismo importante para aquelas espécies que não possuem sementes que germinam sob temperatura constante, revelando capacidade de adaptação e sucesso no estabelecimento, no ambiente que ocorrem (Ekstam et al. 1999; Abdo \& Paula 2006; Simão \& Takaki 2008).

Segundo Simão \& Takaki (2008) a faixa ótima de 25 a $30^{\circ} \mathrm{C}$ para a germinação e as alternâncias diárias de temperaturas de $20-25^{\circ} \mathrm{C}$ indicam que Tibouchina mutabilis apresenta comportamento de uma espécie pioneira e que as alternâncias diárias de temperatura não alteraram a sensibilidade da semente à luz. Para Abdo \& Paula (2006), as temperaturas alternadas de $20-30$ e de $25-35^{\circ} \mathrm{C}$ favorecem o processo germinativo de sementes de Croton floribundus e não há germinação a 15,20 e $40 \mathrm{C}$ ou essa é mínima a $25^{\circ} \mathrm{C}$. Ekstam et al. (1999) mostraram que sementes de Phragmites australis apresentaram alta porcentagem de germinação em temperaturas alternadas, na presença e ausência de luz.

Sementes utilizam a condições de ausência de luz para evitar a germinação e, consequentemente, formar um persistente banco de sementes no solo (Pons 2000). Em Luetzelburgia auriculata, o fato de suas sementes germinarem em ampla faixa de temperatura, no claro e escuro, pode ser uma indicação que a espécie não mantém um permanente banco de sementes no solo e germinem tão logo lhes sejam oferecidos níveis adequados de umidade, de temperatura e de oxigênio. Para Ekstam et al. (1999), a alta porcentagem de germinação de Phragmites australis, no claro e escuro, sugere explicar o fato dessa espécie, apesar da grande produção anual de pequenas sementes, não formar permanente banco de sementes no solo.

Preliminarmente, o processo de germinação de sementes de Luetzelburgia auriculata não se apresenta como fator limitante ao seu recrutamento no ambiente semiárido do Nordeste brasileiro. Contudo, sugere-se o estudo de sua população em área de sua ocorrência, região semiárida, para se conhecer a taxa de recrutamento da espécie e o acompanhamento em casa de vegetação para avaliar o desenvolvimento de suas plântulas.

\section{Conclusões}

As sementes de Luetzelburgia auriculata (Alemão) Ducke germinaram, na presença e na ausência de luz, com as maiores médias alcançadas em $20-40^{\circ} \mathrm{C}, 20^{\circ} \mathrm{C} 25^{\circ} \mathrm{C}, 30^{\circ} \mathrm{C}$ e $35^{\circ} \mathrm{C}$ e as menores em $40^{\circ} \mathrm{C}$. A faixa ótima de temperatura encontra-se entre 25 a $30^{\circ} \mathrm{C}$. A hipótese lançada foi parcialmente corroborada, pois não foi confirmada a previsão das sementes apresentarem as melhores médias de germinação na presença de luz. Suas sementes mostraram-se indiferentes à luz. No entanto, confirma-se a predição de germinação em ampla faixa de temperatura para as sementes desta espécie. É previsível supor o sucesso de seu plantio em regiões com amplitude térmica semelhante à região semiárida do Nordeste do Brasil, onde a espécie ocorre.

\section{Agradecimentos}

Ao Instituto Brasileiro do Meio Ambiente e dos Recursos Naturais Renováveis pela liberação em tempo integral do primeiro autor para realização do Doutorado em Ecologia e Recursos Naturais, no Departamento de Biologia da Universidade Federal do Ceará.

\section{Referências bibliográficas}

Abdo, M.T.V.N. \& Paula, R.C. 2006. Temperaturas para germinação de sementes de capixingui (Croton floribundus - Spreng - Euphorbiaceae). Revista Brasileira de Sementes 28: 135-140

Barbosa, D.C.A. 2008. Estratégias de germinação e crescimento de espécies lenhosas da caatinga com germinação rápida. Pp.625-656. In: Leal, I.R, Tabarelli, M. \& Silva, J.M.C (Eds.). Ecologia e conservação da caatinga. Recife, Editora Universitária da UFPE.

Bond, W.J.; Honig, M. \& Maze, K.E. 1999. Seed size and seedling emergence: an allometric relationship and some ecological implications. Oecologia 120: 132-136.

Buckley, R.C. 1982. Seed size and seedling establishment in tropical arid dunecrest plants. Biotropica 14: 314-315.

Borghetti, F. \& Ferreira, A.G. 2004. Interpretação de resultados de germinação. Pp. 209- 222. In: Ferreira, A.G. \& Borghetti, F. (Ed.). Germinação: do básico ao aplicado. Porto Alegre, Artmed.

Brasil. 2009. Regras para análise de sementes. Brasília, Ministério da Agricultura, Pecuária e Abastecimento, Secretaria de Defesa Agropecuária.

Camara, C.A.; Araújo Neto, J.C.; Ferreira, V.M.; Alves, E.U. \& Moura, F.B.P 2008. Caracterização morfométrica de frutos e sementes e efeito da temperatura na germinação de Parkia pendula (Willd.) Benth. ex Walp. Ciência Florestal 18: 281-290.

Ekstam, B.; Johannesson, R. \& Milberg, P. 1999. The effect of light and number of diurnal temperature fluctuations on germination of $\mathrm{Phrag}$ mites australis. Seed Science Research 9: 165-170.

Felippe, G.M.; Válio, I.F.M.; Pereira, M.F.A.; Sharif, R.R. \& Vieira, S.R. 1983. Fisiologia do desenvolvimento vegetal. Rio de Janeiro, Editora Campus.

Ferreira, D.F. Sisvar 4.3.2003.http://www.dex.ufla.br/danielff/sisvar (Acesso em 02/09/2010).

Gutierrez, J.R.; Aguilera, L.E. \& Moreno, R.J. 1988. The effects of variable regimes of temperature and light on the germination of Atriplex repanda seeds in the semi-arid region of Chile. Revista Chilena de Historia Natural 61: 61-65.

Ipece. Instituto de Pesquisa e Estratégia Econômica do Ceará. Perfil básico municipal: Russas. Disponível: http://www.ipece.ce.gov.br/ (Acesso em 27/01/2011). 
Jankowska-Blaszczuk, M. \& Daws, M.I. 2007. Impact of red:far red ratios on germination of temperate forest herbs in relation to shade tolerance, seed mass and persistence in the soil. Functional Ecology 21: 1055-1062.

Jurado, E.; Estrada, E. \& Molès, A. 2001. Characterizing plant attributes with particular emphasis on seeds in Tamaulipan thornscrub in semi-arid México. Journal of Arid Environments 48: 309-321.

Jurado, E. \& Westoby, M. 1992. Seedling growth in relation to seed size among species of arid Australia. Journal of Ecology 80: 407-416.

Labouriau, L.G. 1983. A Germinação das sementes. Washington, Secretaria-Geral da Organização dos Estados Americanos.

Leishman, M.R.; Wright, I.J.; Moles, A.T. \& Westoby, M. 2000. The evolutionary ecology of seed size. Pp. 31-57. In: FENNER, M. (Ed.). The ecology of regeneration in plant communities. Wallingford, CABI Publishing.

Lima, H.C. 1990. Tribo Dalbergieae (Leguminosae-Papilionoideae) - Morfologia dos frutos, sementes e plântulas e sua aplicação na sistemática. Arquivos do Jardim Botânico do Rio de Janeiro 30: 1-42.

Lorenzi, H. 2008. Árvores brasileiras: manual de identificação e cultivo de plantas arbóreas nativas do Brasil. São Paulo, Instituto Plantarum.

Maguire, J.D. 1962. Speed of germination-aid in selection and evaluation for seedling emergence and vigor. Crop Science 2: 176-177.

Milberg, P.; Andersson, L. \& Thompson, K. 2000. Large seeded species are less dependent on light for germination than small-seeded ones. Seed Science Research 10: 99- 104.

Oliveira, P.G. \& Garcia, Q.S. 2005. Efeitos da luz e da temperatura na germinação de sementes de Syngonanthus elegantulus Ruhland, $S$. elegans (Bong.) Ruhland e S. venustus Silveira (Eriocaulaceae). Acta Botanica Brasilica 19: 639-645.

Pons, T.L. 2000. Seed responses to light. Pp. 237-260. In: Fenner, M. (Ed.) The ecology of regeneration in plant communities. Wallingford, CABI Publishing.

Ramos, M.B.P. \& Varela, V.P. 2003. Efeito da temperatura e do substrato sobre a germinação de sementes de visgueiro do igapó (Parkia discolor
Benth) Leguminosae, Mimosoideae. Revista de Ciências Agrárias 39: 123-133.

Rosa, S.G.T. \& Ferreira, A.G. 2001. Germinação de sementes de plantas medicinais lenhosas. Acta Botanica Brasilica 15: 147-154.

Santana, D.G. \& Ranal, M.A. 2004. Análise da germinação: um enfoque estatístico. Brasília, Editora Universidade de Brasília.

Santos, D.L.; Sugahara, V.Y. \& Takaki, M. 2005. Efeitos da luz e da temperatura na germinação de sementes de Tabebuia serratifolia (Vahl) Nich, Tabebuia chrysotricha (Mart. Ex DC.) Standal. e Tababuia roseo-alba (Ridl) Sand - Bignoniaceae. Ciência Florestal 15: 87-92.

Silva, L.M.M.; Matos, V.P.; Pereira, D.D. \& Lima, A.A. 1995. Morfologia de frutos, sementes e plântulas de Luetzelburgia auriculata Ducke (Pau-Serrote) e Pterogyne nitens Tul (Madeira Nova do Brejo) - Leguminosae. Revista Brasileira de Sementes 17: 154-159.

Simão, E. \& Takaki, M. 2008. Effect of light and temperature on seed germination in Tibouchina mutabilis (Vell.) Cogn. (Melastomataceae). Biota Neotropica 8: 63-68.

Takaki, M. 2005. A luz como fator de estresse na germinação de sementes. Pp. 243-248. In: Nogueira, R.J.M.C.; Araújo, E.L.; Willadino, L.G. \& Cavalcante, U.M.T. (Ed.). Estresses ambientais, danos e benefícios em plantas. Recife, MXM Gráfica e Editora.

Thompson, K. \& Grime, J.P. 1983. A comparative study of germination responses to diurnally-fluctuating temperatures. Journal of Applied Ecology 20: 141-156.

Vásques-Yanes, C. \& Orozco-Segovia, A. 1993. Patterns of seed longevity and germination in the tropical rain forest. Annual Review of Ecology and Systematics 24: 69-87.

Velten, S.B. \& Garcia, Q.S. 2005. Efeitos da luz e da temperatura na germinação de sementes de Eremanthus (Asteraceae), ocorrentes na Serra do Cipó, MG, Brasil. Acta Botanica Brasilica 19: 753-761.

Villalobos, A.E. \& Peláez, D.V. 2001. Influences of temperature and water stress on germination and establishment of Prosopis caldenia Burk. Journal of Arid Environments 49: 321-328. 